\title{
TWO DIGITAL-SCALAR PWM SCHEMES FOR GENERATING THREE-PHASE UNBALANCED VOLTAGES
}

\author{
Darlan A. Fernandes ${ }^{\S}$, Euzeli C. Santos Jr*, Fabiano F. Costa ${ }^{\sharp}$, Alexandre C. Castro ${ }^{\S}$ \\ $\S$ Universidade Federal da Paraíba, CEP:58051-900, João Pessoa - PB, Brasil \\ * Universidade Federal de Campina Grande, CEP:58109-090, Campina Grande - PB, Brasil \\ $\sharp$ Universidade Federal do ABC, CEP:09210-170, Santo André - SP, Brasil \\ darlan@cear.ufpb.br, euzeli@dee.ufcg.edu.br, fabiano.costa@ufabc.edu.br, castro@cear.ufpb.br
}

\begin{abstract}
This paper presents two modulation approaches for generating unbalanced voltages by means of four-leg voltage source inverters (VSI). The first modulation is an extended scheme of a digital scalar pulse width modulation previously proposed for controlling three-leg inverters. The second one is based on the decomposition of the voltage reference signals into their symmetrical components. The schemes are compared theoretically, by simulations and by experimental results. As consequence, it is found out a total equivalence between the two modulations despite their different inspirations. The fundamentals of both techniques and a mathematical proof of their equality are unfolded. Also, the performance of the techniques with respect to the harmonic distortion and power switching loss are discussed. The results show that the techniques are effective.
\end{abstract}

Keywords - Four-Leg Converter, Power Quality, Scalar PWM, Sequence Components, Space Vector PWM, Unbalanced Voltages.

\section{INTRODUCTION}

Pulse width modulation techniques have a central role in the control process of power electronic devices connected to the grid for monitoring and controlling power quality indexes of sensitive and critical loads, allowing the reproduction of the control signals, by means of pulse-width modulation (PWM) techniques. To be effective, these techniques are supposed to reproduce PWM signals with low total harmonic distortion (THD), small delay and be easy to implement in digital signal controllers.

Nowadays, several power electronics devices are applied to mitigate power quality problems. This tendency can be understood as there are an increasing number of sensitive electronic loads with growing control capabilities connected to the utility grid. Most of these problems result in unbalanced current or voltage variations [1]. To compensate these variations, the devices must be able to generate and insert three-phase unbalanced voltages into the power supply by means of a VSI. To provide the neutral, one can use split DClinked capacitors and tying the neutral point to the mid-point of the DC linked [2] or use a four-leg inverter topology and tying the neutral point to the mid-point of the fourth leg [3].

To control the VSI, many modulations techniques has been

Manuscript received 14/12/2011; Revised on 11/02/2012. Accepted for publication 24/02/2012 by recommendation of the Editor Joo Onofre Pereira Pinto. proposed in the literature. When it comes to synthesize balanced voltages, a three-leg, three-wire VSI is sufficient. In this situation, one alternative is to use carrier-based techniques, which can be implemented analogically [4] or digitally, [5]. Other approach is to employ the twodimensional space-vector PWM. This technique is most popular due to their flexibility and good performance in relation to harmonic content [6]. Nevertheless, custom power devices such as dynamic voltage restorers, active power filters, FACTs usually have to compensate the variations with unbalanced voltages [7-9]. To synthesize these voltages, there have been proposed a plethora of methods, mainly based on a four-leg VSI. A common approach of controlling the switching instants is to extend the space-vector analysis to the third-dimension [10-13]. This leads to flexible techniques, with good harmonic content characteristic, but at a cost of higher computational effort and awkward implementation. An interesting technique was proposed in [14], which is also based on the space-vector modulation. The technique makes use of two planes of state vectors to generate asymmetric voltages in lieu of a three dimensional analysis.

Scalar modulation techniques, as opposed to space-vector ones, have the advantage of being computationally more efficient [15], [16]. Nevertheless, these techniques are seldom presented for a four-leg VSI. In [17], it was established a clear equivalence between the space-vector modulation and the digital scalar method. The paper presented a method for implementing the two-dimensional space-vector modulation by using the simpler framework of the digital scalar technique. However, the method was developed for a three-leg VSI to synthesize balanced voltages. Still regarding scalar modulations, a technique based on symmetrical components was proposed in [18]. The implementation of this technique is simple and takes advantage of the fact that many methods for compensating unbalanced voltage signals intrinsically use a decomposition of symmetrical components of the voltages [19], [20].

In this paper, it is proposed an extension of the work presented in [17] to control a four-leg VSI and generate unbalanced voltages. Moreover, it is proved that this technique is equivalent to the one presented in [18]. The paper is organized as follows: The second section briefly describes a digital scalar pulse width modulation (DSPWM) and its equivalence to the well-known space vector pulse width modulation (SVPWM). The third section presents the extended digital scalar pulse width modulation (EDSPWM) which is an adaptation of the DSPWM for controlling the four-leg inverters. The fourth section outlines a modulation 


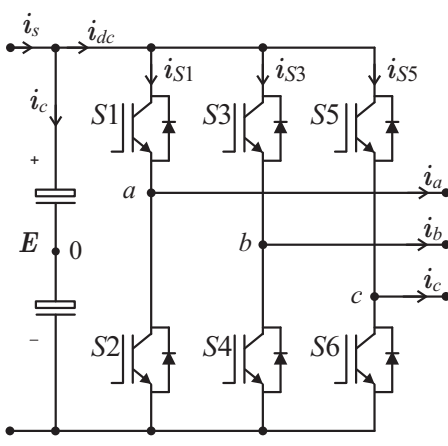

(a)

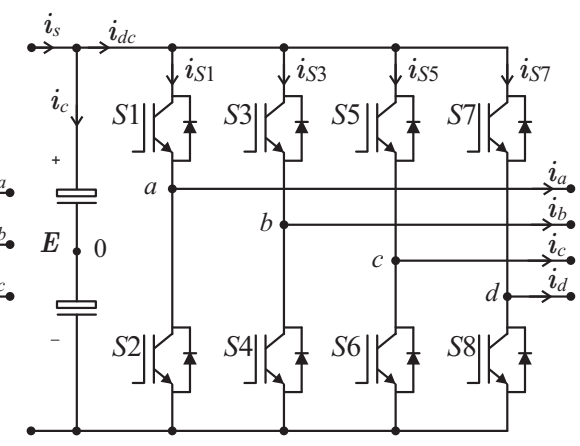

(b)

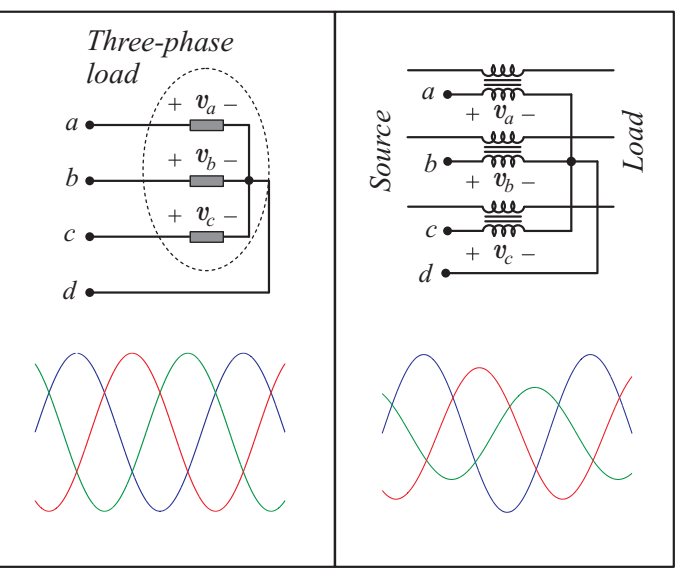

(c)

Fig. 1. Voltage source inverters. (a) Three-legs. (b) Four-legs. (c) Typical applications with three-phase four-wire system demanding: (left) balanced voltages, as in motor drive; and (right) unbalanced voltages, as used in DVR.

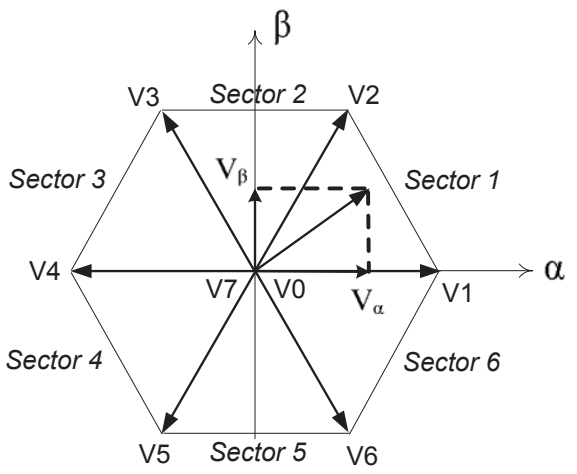

Fig. 2. A space vector located at first sector in the $\alpha \beta$-plane.

technique based on symmetrical components theory, the so-called symmetrical component pulse width modulation (SCPWM). The fifth section demonstrates the equivalence between the two modulations. The results are presented in the sixth section and the conclusions are drawn in the seventh section.

\section{DIGITAL SCALAR PULSE WIDTH MODULATION FOR THREE-LEG INVERTERS}

A sinusoidal three-phase voltage system can be represented by a complex vector rotating in a two-dimensional reference frame. This vector should be used as the reference voltages for the PWM signals in each phase of a three-phase, three-leg VSI. The power converter with a three-phase Y connected load with neutral "n" non interconnected is shown in Figure 1(a).

When the reference sinusoids are balanced, the twodimensional space vector modulation (SVPWM) is widely employed for purpose of PWM generation, due to its flexibility [6]. Figure 2 shows the complex vector in the first sector. On the plane, there are six active voltage vectors of amplitude $\sqrt{\frac{2}{3}} E$, spatially separated $60^{\circ}$ from each other, and two null voltage vectors. The space vector can be represented by a pondered sum of the two adjacent vectors and two null vectors.

Figure 3(a) depicts two adjacent PWM periods. Note that the first period starts at low level whilst the second one starts at high level. The intervals of time $t_{1}$ and $t_{2}$ represent the period where the two adjacent vectors collaborate to the average of the signal. The intervals $t_{01}$ and $t_{02}$ are periods in which all top switches from the inverter are closed or opened. The rate $\mu=t_{01} /\left(t_{01}+t_{02}\right)$ is the so-called "distribution rate" to be arbitrarily fixed.

Alternatively to the SVPWM, the DSPWM imposes to the pole voltage of the inverter $\left(v_{a 0}, v_{b 0}\right.$ and $\left.v_{c 0}\right)$, an average voltage value corresponding to each reference phase within the sampling interval. This strategy is simpler than the SVPWM but does not impose directly the reference to the voltage phases. A version of this technique, proposed in [17], overcomes this problem by adding to the pole references an homopolar voltage $v_{h}$ :

$$
v_{j}^{* \prime}=v_{j}^{*}+v_{h}, \quad j=a, b, c
$$

where voltages $v_{j}^{*}$ are the reference voltage samples desired to be imposed to the phases by the inverter during a PWM period. Thus, as the usual scalar-digital PWM, the pulse widths of the pole voltages are determined by:

$$
\tau_{j}=\left(\frac{v_{j}^{* \prime}}{E}+\frac{1}{2}\right) t_{s}
$$

with $t_{s}$ being the sampling period of the signal and $E$ being the DC voltage of the inverter. Figure 3(b) shows the pulse widths synthesized by the top switches of the inverter. The homopolar voltage $v_{h}$ is defined as:

$$
v_{h}=E\left(\frac{1}{2}-\mu\right)-(1-\mu) v_{M}-\mu v_{m}
$$

with $v_{M}$ and $v_{m}$ being the maximum and minimum voltage value chosen among the three reference voltages for each sampled time.

It has been established a correlation between the DSPWM and the SVPWM techniques. This is useful because the former 

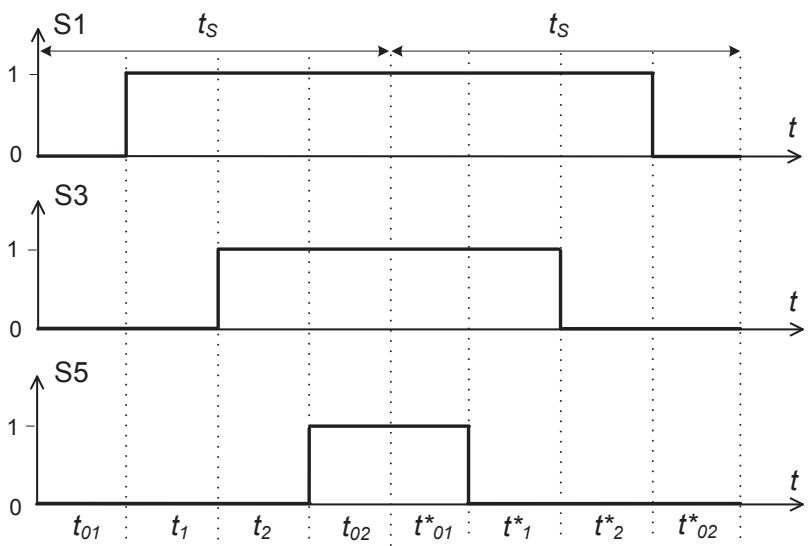

(a)
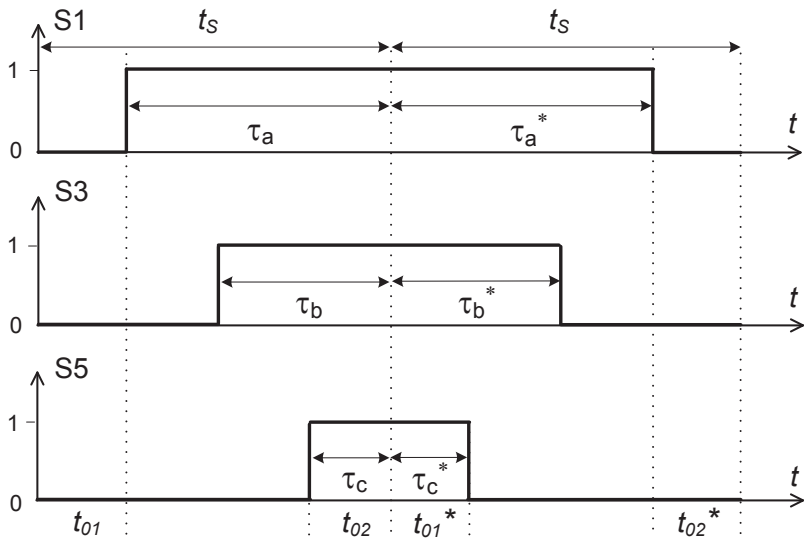

(b)

Fig. 3. Switching functions for generating a space vector in the first sector. (a) Three-phase pulses from SVPWM; (b) Three-phase pulses from DSPWM.

is quite simple to implement, and the latter has desirable features in respect with harmonic distortion. Nevertheless, the DSPWM technique in [17] has not been developed to generate unbalanced voltages. Also, the inverter shown in Fig. 1(a) is not suitable for this task since it has no path for the zero-sequence current. This problem could be solved by connecting the neutral of the load to the middle point of the capacitors. However, such procedure has the disadvantages of reducing the use of DC voltage resulting in higher variations in this voltage. Figure 1(b) (together with load options in the Figure 1(c)) shows a better inverter configuration which overcomes these drawbacks. Next section presents the EDSPWM technique to control such inverter.

\section{EXTENDED DIGITAL-SCALAR PULSE WIDTH MODULATION - EDSPWM}

The idea behind this technique is to impose the homopolar voltage $v_{h}$ to the pole $d$ of a fourth leg. Thus, it follows:

$$
\begin{aligned}
& v_{a}^{* \prime}=v_{a}^{*}+v_{h} \\
& v_{b}^{* \prime}=v_{b}^{*}+v_{h} \\
& v_{c}^{* \prime}=v_{c}^{*}+v_{h} \\
& v_{d}^{* \prime}=0+v_{h} .
\end{aligned}
$$

This procedure assures that any desired references $v_{a}^{*}, v_{b}^{*}$, and $v_{c}^{*}$ will be imposed to the voltage phases of the load. This can be verified by examining the circuit path "ad0a" in Figure 1(b). Thus, for phase $a$, one can write:

$$
v_{a d}=v_{a 0}-v_{d 0} .
$$

As voltages $v_{a 0}$ and $v_{d 0}$ are imposed to be equal to the references $v_{a}^{* \prime}$ and $v_{d}^{* \prime}$ through the switches $S_{1}, S_{2}, S_{7}$ and $S_{8}$, one can have any set of voltage phases, balanced or not. The pulse widths are determined as:

$$
\begin{aligned}
\tau_{a} & =\left(\frac{v_{a}^{* \prime}}{E}+\frac{1}{2}\right) t_{s}, \\
\tau_{b} & =\left(\frac{v_{b}^{* \prime}}{E}+\frac{1}{2}\right) t_{s}, \\
\tau_{c} & =\left(\frac{v_{c}^{* \prime}}{E}+\frac{1}{2}\right) t_{s}, \\
\tau_{d} & =\left(\frac{v_{d}^{* \prime}}{E}+\frac{1}{2}\right) t_{s},
\end{aligned}
$$

\section{SYMMETRICAL-COMPONENT PULSE WIDTH MODULATION - SCPWM}

An alternative approach for generating unbalanced threephase voltage references with a 4-leg inverter uses a scalar modulation based on the symmetrical components theory. The idea is to take advantage of an instantaneous component symmetric transformation presented in [21]. Thus, if $v_{a}^{*}$, $v_{b}^{*}$, and $v_{c}^{*}$ are the instantaneous unbalanced voltage values to be reproduced by the inverter, one can extract the zero sequence from these values to obtain the sum of the positive and negative symmetrical sequences $v_{a s}^{*}, v_{b s}^{*}$, and $v_{c s}^{*}$. In turn, zero-sequence values must be added to the homopolar voltage $v_{h s}$ defined analogously to (3):

$$
v_{h s}=E\left(\frac{1}{2}-\mu\right)-(1-\mu) v_{M s}-\mu v_{m s}
$$

with $v_{M s}$ and $v_{m s}$ now being the maximum and minimum values chosen among $v_{a s}^{*}, v_{b s}^{*}$ and $v_{c s}^{*}$ for each sampled time. Therefore, one can write the pulse widths to the pole voltages as:

$$
\begin{aligned}
\tau_{1} & =\left(\frac{v_{a s}^{* \prime}}{E}+\frac{1}{2}\right) t_{s} \\
\tau_{2} & =\left(\frac{v_{b s}^{* \prime}}{E}+\frac{1}{2}\right) t_{s} \\
\tau_{3} & =\left(\frac{v_{c s}^{* \prime}}{E}+\frac{1}{2}\right) t_{s}
\end{aligned}
$$


where $v_{a s}^{* \prime}=v_{a s}^{*}+v_{h s}, v_{b s}^{* \prime}=v_{b s}^{*}+v_{h s}$, and $v_{c s}^{* \prime}=v_{c s}^{*}+v_{h s}$.

If these pulses were applied to the poles of the inverter, they would impose the sum of positive and negative symmetrical voltages across the phases of the load. To take into account the zero sequence, first, consider the situation where the fourth leg is not operating (switches $S 7$ and $S 8$ are open). If $S 1$ close and $S 3$ and $S 5$ opened, the phase voltages are $\frac{2}{3} E,-\frac{1}{3} E$ and $-\frac{1}{3} E$. Now, consider the closuring of $S 8$, without changing the positions of the other switches. The phase voltages are:

$$
\begin{gathered}
v_{a n}=E=\frac{2}{3} E+\frac{1}{3} E \\
v_{b n}=0=-\frac{1}{3} E+\frac{1}{3} E \\
v_{c n}=0=-\frac{1}{3} E+\frac{1}{3} E .
\end{gathered}
$$

The phase voltages are the same as those generated by the 3 legs but with the addition of a zero sequence voltage to each one of the phase voltages. Table I shows the zero sequence voltage generated by the fourth leg with the switches in the first three legs set to generate the state vectors.

\section{TABLE I}

Zero sequence voltage generated in each state

\begin{tabular}{ccc}
\hline & \multicolumn{2}{c}{ Zero sequence voltage } \\
State & S7 & S8 \\
\hline V0 & 0 & $E$ \\
\hline $\mathrm{V} 1$ & $-\frac{2}{3} E$ & $\frac{1}{3} E$ \\
\hline $\mathrm{V} 2$ & $-\frac{1}{3} E$ & $\frac{2}{3} E$ \\
\hline $\mathrm{V} 3$ & $-\frac{2}{3} E$ & $\frac{1}{3} E$ \\
\hline $\mathrm{V} 4$ & $-\frac{1}{3} E$ & $\frac{2}{3} E$ \\
\hline $\mathrm{V} 5$ & $-\frac{2}{3} E$ & $\frac{1}{3} E$ \\
\hline $\mathrm{V} 6$ & $-\frac{1}{3} E$ & $\frac{2}{3} E$ \\
\hline $\mathrm{V} 7$ & $-E$ & 0 \\
\hline
\end{tabular}

Now consider the switching sequence shown in Table II for generating a space vector in any sector of the diagram shown in Figure 2. The phase voltages for the 4-leg converter are the sum of the corresponding voltages for the 3-leg inverter and a zero sequence voltage which varies during the switching period as shown in Figure 4. The two stepped waveforms shown in this figure result from the closure of $S 8$ or $S 7$. Note that the stepped waves are vertically displaced from each other by the constant voltage of the DC-link.

TABLE II

Switching sequences for generating PWM pulses

\begin{tabular}{cccccccc}
\hline Sector & \multicolumn{7}{c}{ Switching sequence } \\
\hline 1 & V7 & V1 & V2 & V0 & V2 & V1 & V7 \\
\hline 2 & V7 & V3 & V2 & V0 & V2 & V3 & V7 \\
\hline 3 & V7 & V3 & V4 & V0 & V4 & V3 & V7 \\
\hline 4 & V7 & V5 & V4 & V0 & V4 & V5 & V7 \\
\hline 5 & V7 & V5 & V6 & V0 & V6 & V5 & V7 \\
\hline 6 & V7 & V1 & V6 & V0 & V6 & V1 & V7 \\
\hline
\end{tabular}

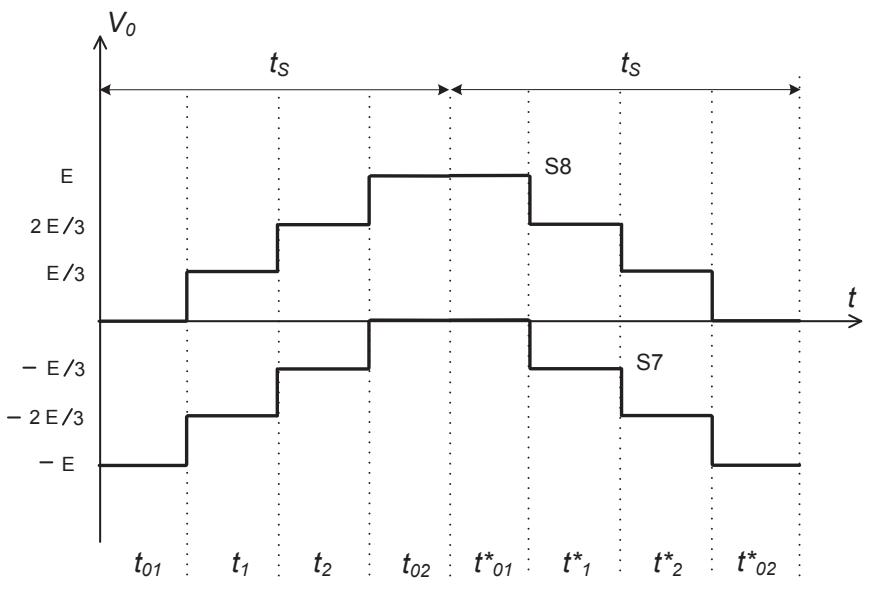

Fig. 4. Zero sequence voltage variation during any switching period.

Now, sort $\left(\tau_{1}, \tau_{2}, \tau_{3}\right)$ into $\left(\tau_{\min }, \tau_{i}, \tau_{\max }\right)$. Then, it is fixed:

$$
\begin{aligned}
& t_{1}=\left(\tau_{\max }-\tau_{i}\right) / 2 \\
& t_{2}=\left(\tau_{i}-\tau_{\min }\right) / 2 .
\end{aligned}
$$

Suppose $\mu=0.5$, i.e., $t_{01}=t_{02}=t_{z}$. Also, suppose that $S 8$ is closed during a switching period, except during an interval $\tau_{4}$ when the switch $S 7$ is closed. Then the zero sequence voltage generated during this switching period is given by:

$$
v_{0}=E\left[\frac{1}{2}-\frac{\left(t_{1}-t_{2}\right)}{6 t_{s}}\right]-\frac{\tau_{4}}{t_{s}} E .
$$

Therefore, the switching interval for $S 7$ required for generating a given zero sequence voltage $v_{0}$ is

$$
\tau_{4}=t_{s}\left(\frac{1}{2}-\frac{v_{0}}{E}\right)-\frac{t_{1}-t_{2}}{6} .
$$

Summarizing, the SCPWM scheme for the 4-leg inverter is given by the following steps:

(i) Determine $\tau_{1}, \tau_{2}$ and $\tau_{3}$ (equations (14)-(16)).

(ii) Determine the intervals $t_{1}, t_{2}$ (equations (20) and (21)).

(iii) Determine the interval $\tau_{4}$ for the fourth leg, as given by (23). Figure 5 shows the switching function for $S 7$.

Note that the SCPWM is also a kind of digital-scalar PWM, since there is no need to define a complex vector for a sinusoidal 3-phase reference.

\section{EQUIVALENCE BETWEEN EDSPWM AND SCPWM}

A strict comparison between the two modulation schemes here proposed must be carried out by comparing the pulses $\left(\tau_{1}, \tau_{2}, \tau_{3}, \tau_{4}\right)$ with $\left(\tau_{a}, \tau_{b}, \tau_{c}, \tau_{d}\right)$.

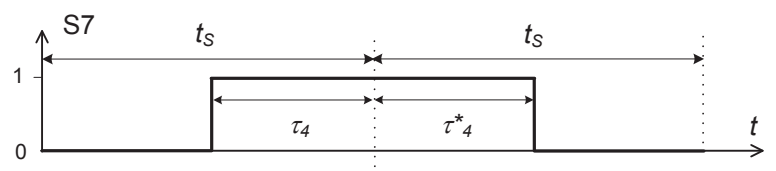

Fig. 5. Switching function for $S 7$. 
To prove that $\tau_{1}$ and $\tau_{a}$ are equal, it is enough to show that $v_{a}^{* \prime}$ is equivalent to $v_{a s}^{* \prime}$. Thus, by definition:

$$
\begin{gathered}
v_{a}^{*}=v_{a s}^{*}+v_{0} \\
v_{M}=v_{M s}+v_{0} \\
v_{m}=v_{m s}+v_{0} .
\end{gathered}
$$

Substituting (25) and (26) in (3), it follows:

$$
v_{h}=v_{h s}-v_{0} .
$$

Finally, substituting (24) and (27) in (4), and having in mind (13), one readily finds:

$$
v_{a}^{* \prime}=v_{a s}^{*}+v_{h s} .
$$

Thus, $v_{a}^{* \prime}=v_{a s}^{* \prime}$, which means that $\tau_{1}=\tau_{a}$. Analogous argument may be applied to find $\tau_{2}=\tau_{b}$ and $\tau_{3}=\tau_{c}$.

To show the equivalence between pulses $\tau_{d}$ and $\tau_{4}$, first one has to rewrite (9)-(11), using (4)-(6):

$$
\begin{aligned}
v_{a}^{*}+v_{h} & =\frac{\tau_{a}-\left(t_{s}-\tau_{a}\right)}{t_{s}} E \\
v_{b}^{*}+v_{h} & =\frac{\tau_{b}-\left(t_{s}-\tau_{b}\right)}{t_{s}} E \\
v_{c}^{*}+v_{h} & =\frac{\tau_{c}-\left(t_{s}-\tau_{c}\right)}{t_{s}} E .
\end{aligned}
$$

Now observing Figure 3, one can write:

$$
\begin{aligned}
\tau_{a} & =t_{1}+t_{2}+t_{02} \\
\tau_{b} & =t_{s}-t_{01}-t_{1} \\
\tau_{c} & =t_{02}
\end{aligned}
$$

and keeping in mind that

$$
v_{a}+v_{b}+v_{c}=3 v_{0}
$$

one can sum up (29)-(31), and after some manipulation write:

$$
v_{h}=-v_{0}+\frac{-t_{1}+t_{2}}{6 t_{s}} E+\frac{t_{02}-t_{01}}{2 t_{s}} E .
$$

Then, substituting (36) in (12) to write:

$$
\tau_{d}=\left[\frac{-v_{0}}{E}+\frac{-t_{1}+t_{2}}{6 t_{s}}+\frac{t_{02}-t_{01}}{2 t_{s}}\right] t_{s}+\frac{1}{2} t_{s}
$$

and finally, setting $\mu=0.5$, that is $t_{01}=t_{02}$, the expression for $\tau_{d}$ is given by:

$$
\tau_{d}=t_{s}\left(\frac{1}{2}-\frac{v_{0}}{E}\right)-\frac{t_{1}-t_{2}}{6}
$$

which is equal to (23).

Thus the pulse widths produced by EDSPWM and the SCPWM techniques have equivalent equations. This means the schemes generate the same unbalanced three-phase voltages.

\section{RESULTS}

The first part of this section is comprised by simulations carried out to corroborate the equivalence of the EDSPWM and SCPWM modulation techniques. The second one presents the experimental results. Also, it is shown the effectiveness of these techniques by comparing them with a space vector modulation proposed in [14]. All the results presented here were generated with a PWM cycle, $t_{s}$ of $100 \mu s$.

\section{A. Simulated results}

To begin with, the EDSPWM and SCPWM modulations will be used to synthesize references of unbalanced voltages with the following characteristics: phase $\mathrm{A}\left(V_{a n}\right)$ has magnitude of $100 \mathrm{~V}$, phase $\mathrm{B}\left(V_{b n}\right)$ of $70 \mathrm{~V}$, and phase $\mathrm{C}$ $\left(V_{c n}\right)$ of $90 \mathrm{~V}$. The references are shifted of $120^{\circ}$ from each other. Figure 6 shows the modulated voltages synthesized by the converter phases from both techniques. It is clear the equivalence between the two methods. To demonstrate that the methods are producing the correct references, the fundamental phases of the modulated signals are shown in Figure 7. As can be noted, there is an agreement between them and the reference signals.

To investigate the performance of the EDSPWM with respect to the harmonic content, Figure 8 plots the weighted total harmonic distortion (WTHD) for the EDSPWM and for the technique presented in [14] in relation to the modulation index, $M$, defined as:

$$
M=\frac{\sqrt{3} V}{E},
$$

where $V$ is the highest peak among the three sinusoid references to be reproduced. It was established an asymmetry pattern for the three-phase voltages. Thus, for each modulation index value, phase $\mathrm{A}$ is a reference, phase $\mathrm{B}$ is fixed to $70 \%$ of A and phase C to $90 \%$ of A. The DC link voltage $E$ is constant. In this figure, the technique proposed in [14] is labeled 4-leg SVPWM, since is, in fact, a kind of space vector used in four-leg inverters. The two modulations were implemented for a distribution rate, $\mu$, equal to 0.5 . From the figure, one can infer that for most values of $M$, the EDSPWM technique is advantageous over the 4-leg SPWM. This fact is accentuated for higher values of $M$.

Other important feature to be examined in any modulation technique is its behavior regarding the power losses resulting from the VSI switching. In this work, the loss estimation was based on the work presented in [22]. The tests presented here made use of a dual-module CM50DY-24H (POWEREX) insulated-gate bipolar transistor (IGBT) driven by a SKHI23 (SEMIKRON). The switch loss model includes: 1) IGBT and diode conduction losses; 2) IGBT turn-on losses; 3) IGBT turn-off losses; and 4) diode turn-off energy. Figure 9 compares the EDSPWM with the 4-leg SPWM, from reference [14]. It shows a normalized loss for the two techniques plotted against the modulation index. From the figure, one concludes that again the EDSPWM has a superior performance. This result can be better understood if one determines the average number of switching per cycle for each modulation. Table III summarizes these numbers for the three 
(a) $\underset{\substack{\mathrm{E} \\ \text { 焉 }}}{\sum}$
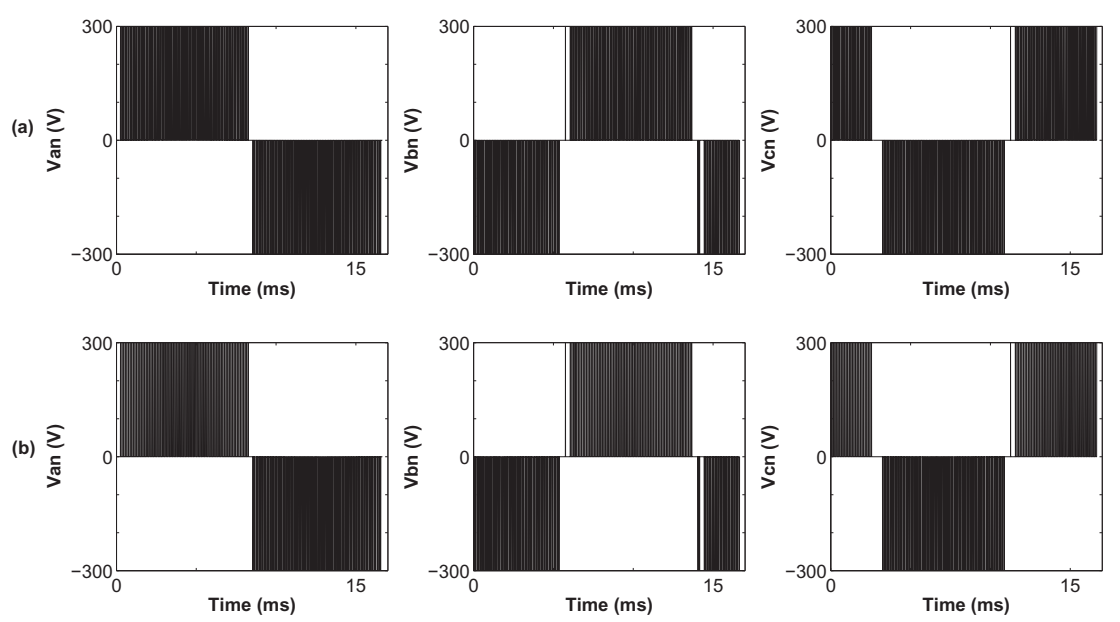

Fig. 6. Unbalanced modulated voltages produced by techniques: (a) EDSPWM; (b) SCPWM.

(a)
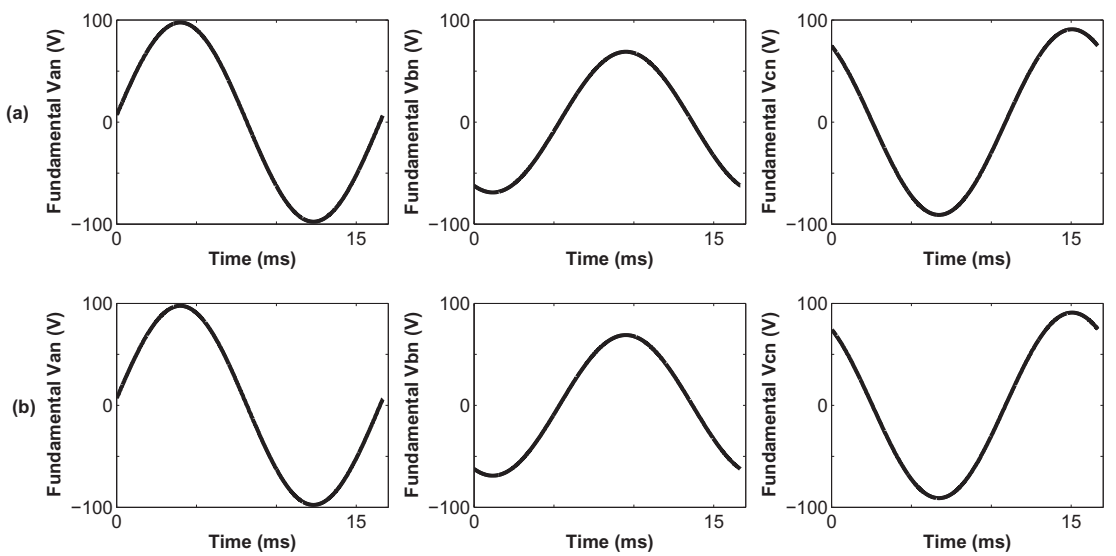

Fig. 7. Fundamental phases generated by techniques: (a) EDSPWM; (b) SCPWM.

modulations methods. As previously stated, the EDSPWM and the SCPWM present the same results.

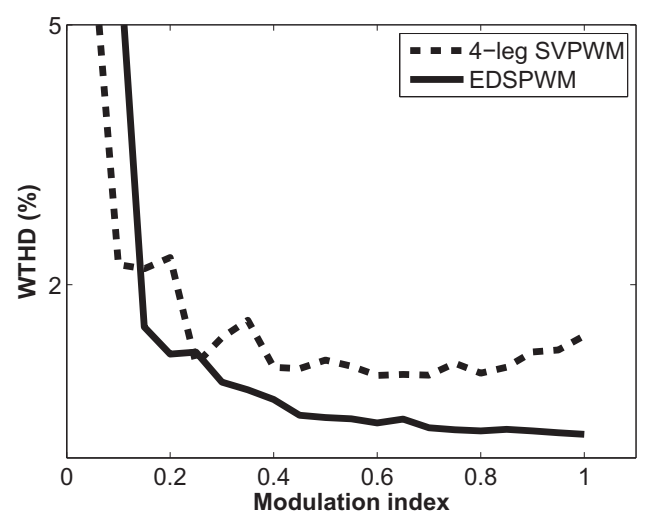

Fig. 8. Weighted total harmonic distortion variation with respect to the modulation index.

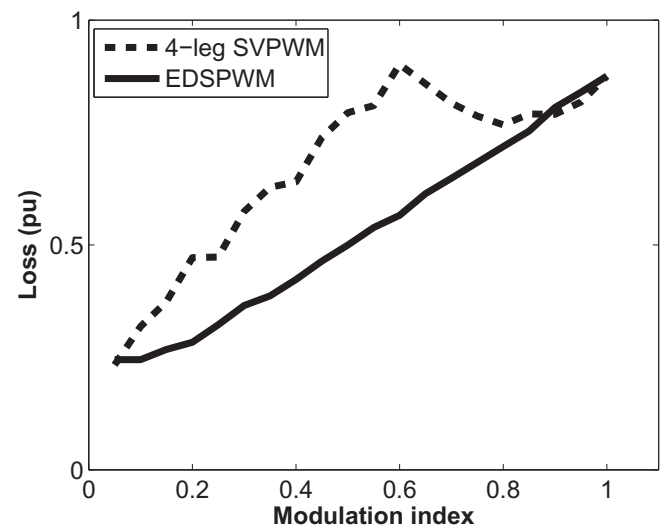

Fig. 9. Power loss variation with respect to the modulation index.

\section{B. Experimental results}

The experimental apparatus used to implement the modulation techniques comprises a four-leg VSI, with an acquisition and processor system. The DC bus voltage was 
TABLE III

Comparison of PWM schemes in respect to the number of switching per PWM period

\begin{tabular}{cccc}
\hline & EDSPWM & SCPWM & 4-leg SVPWM \\
\hline Number of switching & 16 & 16 & 24 \\
\hline
\end{tabular}

set in $300 \mathrm{~V}$ and the PWM cycle, $t_{s} 100 \mu s$. The reference voltages to be generated are the same of the simulated cases. Figure 10(a) and 10(b) show respectively the modulated phases $V_{a n}, V_{b n}$ and $V_{c n}$ for the EDSPWM and the SCPWM techniques. As expected, they are identical. The fundamental phases are measured in Figure 11(a) and 11(b). They are filtered waveforms from the corresponding modulated voltages. Again, it is demonstrated the equivalence between the techniques.

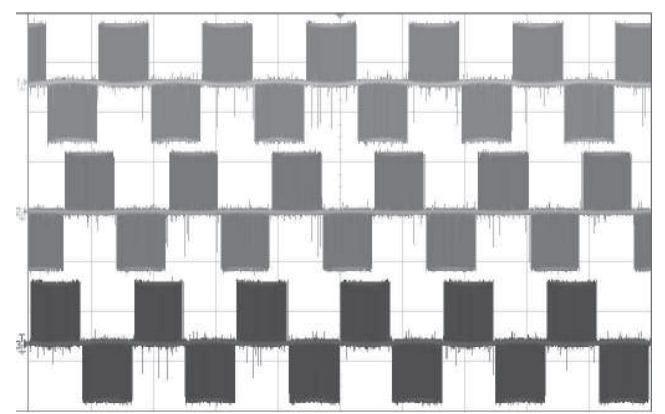

(a) Modulated phase voltages for the EDSPWM. Vertical scale $=165 \mathrm{~V} /$ div .

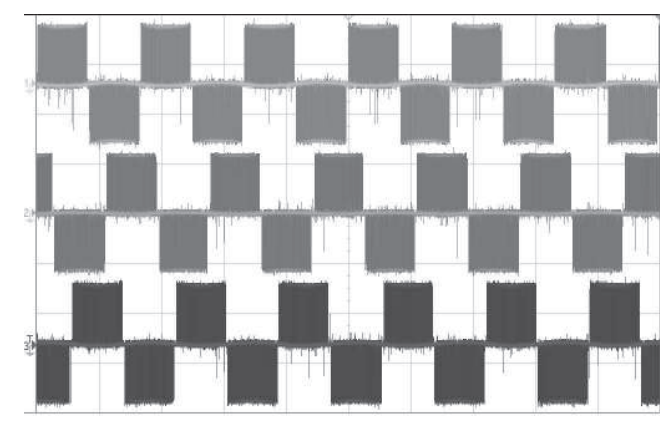

(b) Modulated phase voltages for the SCPWM. Vertical scale $=165 \mathrm{~V} / \mathrm{div}$

Fig. 10. Modulated phase voltages.

\section{CONCLUSION}

This paper has presented two modulation schemes for generating unbalanced voltages by means of four-leg voltage source inverters. One technique, the EDSPWM, is new and is an extended version of the one proposed for three legs, whilst the other, called here SCPWM, was originally proposed from the use of sequence components. Moreover, it is analytically proved the complete equivalence between the two techniques. This was then showed through simulations and experimental implementations. Both techniques may be classified as scalar techniques and are of simple implementation. As opposed to the SCPWM, the EDSPWM directly imposes asymmetrical voltages on the phases without any symmetrical components

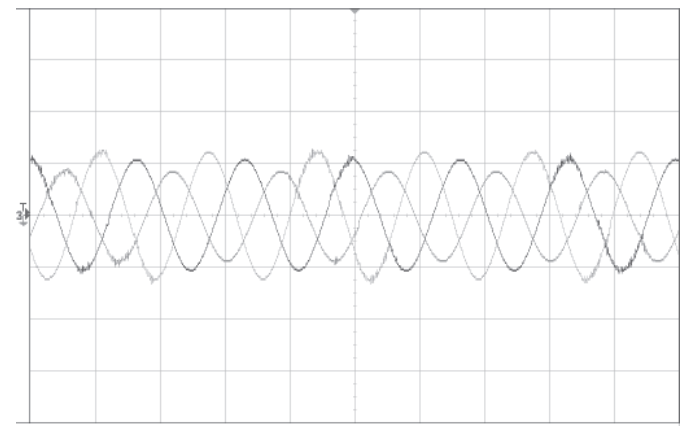

(a) Fundamental phase voltages for the EDSPWM. Vertical scale $=85 \mathrm{~V} /$ div .

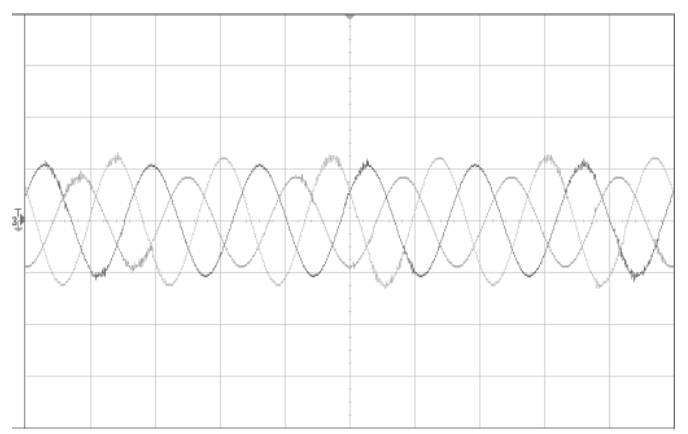

(b) Fundamental phase voltages for the SCSPWM. Vertical scale $=85 \mathrm{~V} /$ div .

Fig. 11. Fundamental phase voltages.

separation. The results showed that both techniques presented good qualities regarding harmonic distortion and switching losses.

\section{ACKNOWLEDGEMENT}

The authors would like to thank Brazilian Research Council $\mathrm{CNPq}$ for providing financial support by means of project 481950/2009-5 and FAPESP project 10/01690-2.

\section{REFERENCES}

[1] M. H. J. Bollen. Understanding Power Quality Problems - Voltages Sags and Interruptions. IEEE Press, New York, N.Y., 2000.

[2] M. Dai, M. Nanda Marwali, J.-W. Jung, and A. Keyhani. A three-phase four-wire inverter control technique for a single distributed generation unit in island mode. IEEE Transactions on Power Electronics, 23(1):322331, January 2008.

[3] N.-Y. Dai, M.-C. Wong, F. Ng, and Y.-D. Han. A FPGAbased generalized pulse width modulator for three-leg center-split and four-leg voltage source inverters. IEEE Transactions on Power Electronics, 23(8):1472-1484, May 2008.

[4] S. Fukuda and Y. Iwaji. Introduction of the harmonic distortion determining factor and its application to evaluating real time PWM inverters. IEEE Transactions on Industry Applications, 31(1):149-154, January/February 1995.

[5] Z. Chen, H. Mao, X. Yang, and Z. Wang. A study on pulse width errors of digitized naturally sampled PWM. 
In IEEE Power Electronics Specialists Conference, PESC 2008, pages 592 - 597, 2008.

[6] H. W. Van der Broeck, H. C. Skudelny, and G. V. Stanke. Analysis and realization of a pulsewidth modulator based on voltage space vector. IEEE Transactions on Industry Applications, 24(1):142-150, Jan/Feb 1988.

[7] G. Venkataramanann B. Wang and M. Illindala. Operation and control of a dynamic voltage restorer using transformer coupled $\mathrm{H}$-bridge converters. IEEE Transactions on Power Electronics, 21(4):1053-1061, July 2006.

[8] H. Yong, J. Xiaohua, and J. Jianguo. Parallel processing UPS and unbalanced voltage sag compensation. In Proc. of IPEMC, pages 972-976, 2004.

[9] G.-M. Lee, D.-C. Lee, and J.-K. Seok. Control of series active power filters compensating for source voltage unbalance and current harmonics. IEEE Transactions on Industrial Electronics, 51(1):132-139, Feb 2004.

[10] W. F. Souza, M. A. S.-Mendes, and P. F. Seixas. PWM vetorial para inversor trifásico de quatro-braços. Eletrônica de Potência - SOBRAEP, 12(2):89-96, Julho 2007.

[11] X. Li, Z. Deng, Z. Chen, and Q. Fei. Analysis and simplification of three-dimensional space vector PWM for three-phase four-leg inverters. IEEE Transactions on Industry Applications, 58(2):450-454, Feb 2011.

[12] R. R. Sawant and M. C. Chandorkar. A multifunctional four-leg grid-connected compensator. IEEE Transactions on Industry Applications, 45(1):249-259, Jan/Feb 2009.

[13] I. J. Gabe, J. P. Costa, M. Stefanello, and H. Pinheiro. Modulação space vector estendida a conversores estáticos com braços em paralelo. Eletrônica de Potência SOBRAEP, 12(3):205-216, Nov 2007.

[14] O. Ojo and P. Kshirsagar. Concise modulation strategies for four-leg voltage source inverters. IEEE Transactions on Power Electronics, 19(1):46-53, Jan 2004.

[15] M. I. Marei, E. F. El-Saadany, and M. M. A. Salama. Three-dimensional feedforward space vector modulation applied to multilevel diode-clamped converters. IEEE Transactions on Industrial Electronics, 56(1):101-109, January 2009.

[16] Y. Zhang, Z. Zhao, and J. Zhu. A hybrid PWM applied to high-power three-level inverter-fed inductionmotor. IEEE Transactions on Industrial Electronics, 58(8):3409-3420, Aug 2011.

[17] C. B. Jacobina, A. M. N. Lima, E. R. C. da Silva, R. N. C. Alves, and P. F. Seixas. Digital scalar pulsewidth modulation: A simple approach to introduce nonsinusoidal modulating waveforms. IEEE Transactions on Power Electronics, 16(3):351-359, May 2001.

[18] S. R. Naidu and D. A. Fernandes. Generation of unbalanced 3-phase voltages for dynamic voltage restoration using the 4-leg voltage source converter. In IEEE Power Electronics Specialists Conference, PESC 2003, pages $17-21,2007$.

[19] S. R. Naidu and D. A. Fernandes. Dynamic voltage restorer based on 4-leg voltage source converter. IET Gen. Transm. Distrib., 3(5):437-447, May 2009.
[20] M. I. Marei, E. F. El-Saadany, and M. M. A. Salama. A new approach to control DVR based on symmetrical components estimation. IEEE Transactions on Power Delivery, 22(4):2017-2024, Oct 2008.

[21] D. A. Fernandes, S. R. Naidu, and C. A. E. Coura Jr. Instantaneous sequence-components resolution of 3phase variables and its application to dynamic voltage restoration. IEEE Transactions on Instrumentation and Measurement, 58(8):2580-2587, Aug 2009.

[22] M. C. Cavalcanti, E. R. C. Silva, D. Boroyevich, W. Dong, and C. B. Jacobina. A feasible loss model for IGBT in soft-switching inverters. In IEEE Power Electronics Specialists Conference, PESC 2003, volume 4, pages 1845 - 1850, 2003.

\section{BIOGRAPHIES}

Darlan A. Fernandes received the B.S. degree in electrical engineering from the Universidade Federal da Paraíba in 2002, and M.S. and Ph.D. degrees in electrical engineering from the Universidade Federal de Campina Grande, in 2004 and 2008, respectively. From 2007 to 2011, he was a Professor at the Industry Department in the Instituto Federal de Educação, Ciência e Tecnologia do Rio Grande do Norte. He is currently Professor at Electrical Engineering Department in the Universidade Federal da Paraíba. His research interests are in the applications of power electronics in power systems and power quality. Professor Darlan is SOBRAEP and IEEE member.

Euzeli C. dos Santos Jr. received the B.S., M.S., and Ph.D. degrees in electrical engineering from the Federal University of Campina Grande (UFCG), in 2004, 2005, and 2007, respectively. He was a Visiting Scholar with Electric Machines and Power Electronics Laboratory, Texas A\&M University, College Station, from 2006 to 2007. From August 2006 to March 2009, he was a Professor at the Federal Center of Technological Education of Paraíba. From December 2010 to March 2011, he was a Visiting Professor at the University of Siegen, Germany, sponsored by DAAD/CAPES. Since March 2009, he has been a Professor in Electrical Engineering (UFCG). His research interests include power electronics and electrical drives.

Fabiano F. Costa received the B.S., M.S. and PhD. degrees from University of São Paulo (USP), Federal University of Paraíba (UFPB) and University of Campina Grande (UFCG) in 1997, 2001 and 2005 respectively, all in electrical engineering. He is presently an Assistant Professor at the Department of Electrical Engineering in Federal University of ABC (UFABC). His research interests include digital signal processing, power quality and modeling of dynamic systems.

Alexandre C. Castro received the B.S. and M.S. degrees in electrical engineering from the Universidade Federal da Paraíba (UFPB) in 1995 and 2000, respectively. In 2006 received the $\mathrm{Ph} . \mathrm{D}$. degree in mechanical engineering from the UFPB. From 2002 to 2009, he was a Professor in the Instituto Federal de Educação, Ciência e Tecnologia da Bahia. He is currently Professor at Electrical Engineering Department in the UFPB. His research interests are in the control applications in power systems and power quality. 